\title{
Os 10 anos da Sociologia no ensino médio no Brasil: considerações sobre a formação de professores de Ciências Sociais na UFSM
}

Ceres Karam Brum

\section{Resumo}

O artigo objetiva efetuar um balanço da formação de professores de Ciências Sociais no Brasil, iniciado com a promulgação de lei da Lei n 1 1.684/ 2008 (que tornou obrigatório o ensino de Sociologia e da Filosofia no ensino médio), que se finaliza com a reforma do ensino médio e a Base Nacional delineada na Lei $n^{\circ}$ 13.415/2017. Para tanto pretendo focalizar a experiência de trabalho com as disciplinas de Ciências Sociais para o Ensino Médio e Antropologia da Educação, a partir das transformações ocorridas no Departamento de Ciências Sociais da Universidade Federal de Santa Maria (UFSM), que levaram à criação dos cursos de Licenciatura em Sociologia e Ciências Sociais nas modalidades presencial e EAD. Em um segundo momento, pretendo propor algumas ações reflexivas para os tempos que se anunciam, efetuando uma recuperação do conceito antropológico de educação, para colocá-lo em ação e, a serviço da formação de licenciados em Ciências Sociais no Brasil, para, como conclusão, expressar novas vias de acesso às Ciências Sociais na escola.

Palavras-chave: sociologia, ensino médio, formação de professores

\section{Considerações preliminares}

$\mathrm{Na}$ atualidade educacional brasileira estamos vivendo tempos de incerteza e de mudanças. Segundo o entendimento dos autores Ferreti e Silva (2017, p. 391), tivemos a passagem de um neoliberalismo de terceira via (contexto no qual ocorreu a promulgaçáo da Lei no $11.684 / 2008$, que tornou obrigatório o ensino de Sociologia e da Filosofia no ensino médio),

I Professora do Departamento de Ciências Sociais da Universidade Federal de Santa Maria. cereskb@terra.com.br

$(\infty)$ EY
Direito autoral e licença de uso: Este artigo está licenciado sob uma Licença Creative Commons. Com essa licença você pode compartilhar, adaptar, para qualquer fim, desde que atribua a autoria da obra, forneça um link para a licença, e indicar se foram feitas alterações. 
para o acirramento de políticas neoliberais tradicionais que propóem uma formação voltada para a "profissionalização" como objetivo preponderante do ensino médio no Brasil. Tais mudanças se expressam na recente reforma do ensino médio, delineada na Lei no $13.415 / 2017$ e na proposta de uma nova Base Nacional Comum Curricular.

Esse novo cenário nos incita a um conjunto de reflexôes sobre os rumos do ensino médio no Brasil e nos exige um exame da experiência de uma década de Sociologia na escola, para tentar entender as razóes destas transformaçóes e as perspectivas formativas que se anunciam.

Para realizar um balanço destes dez anos, ao mover-me em um universo de análise entre os dois diplomas legais, pretendo rememorar meu percurso, sublinhando alguns elementos que entendo como presentes na formação de professores em Ciências Sociais. Tais elementos afloraram da minha experiência de trabalho com as disciplinas de Ciências Sociais para o Ensino Médio e Antropologia da Educação, em razão das transformaçóes ocorridas no Departamento de Ciências Sociais da Universidade Federal de Santa Maria (UFSM), que levaram à criação dos cursos de Licenciatura em Sociologia e Ciências Sociais nas modalidades presencial e EAD.

Em um segundo momento, pretendo efetuar um novo exercício de estranhamento sobre o atual quadro legal brasileiro e das amarras curriculares e formativas que nos impinge. Desejo, neste sentido, propor algumas açóes reflexivas para os tempos que se anunciam, com seus desafios de profunda transformação na formação de professores no Brasil. De professores em Ciências Sociais que de certa forma perderam a referência obrigatória da Sociologia no Ensino Médio, sem que tenha desaparecido a necessidade da existência de uma Sociologia no currículo que se justifica cada vez mais. Minha proposta é de efetuar uma recuperaçáo do conceito antropológico de educação, para colocá-lo em ação e, a serviço da formação de licenciados em Ciências Sociais no Brasil, para, como conclusão, expressar novas vias de acesso às Ciências Sociais na escola.

\section{Percurso}

Em 2007, em uma noite fria de agosto, iniciei minha aula de História da Educação para a turma especial de Licenciados em Ciências Sociais com a seguinte indagação: 
- Vocês já refletiram sobre como pretendem efetuar a seleção de tópicos a serem abordados na disciplina de Sociologia no ensino médio, já que ela possui apenas 50 minutos por semana?

Uma estudante levantou a mão e disse que não estava entendendo:

- Professora de qual programa está falando? A escola onde eu vou estagiar não tem programa, o governo também não disponibiliza nas Diretrizes nem nas Orientações. A Sociologia parece que não existe, nem obrigatória ainda ela é.

O diálogo que rememorei situa o estranhamento inicial que em parte desencadeou meu envolvimento com a temática das Ciências Sociais para o ensino médio, as atividades de pesquisa, de ensino e de gestáo que desenvolvi na UFSM desde entáo. Naquele momento percebi o quanto eu estava despreparada e desorientada, mas que, por outro lado, minha situação se comunicava com a angústia vivenciada por meus estudantes já em situação de estágio.

A disciplina de História da Educação se inseria na formação complementar do conhecido "Modelo 3 mais 1" do Curso de formação de Licenciados em Ciências Sociais, organizado pelo Departamento de Ciências Sociais com vistas a complementar a formação e propiciar habilitação aos bacharéis em Ciências Sociais egressos da instituição. Este curso de quatro semestres visava a habilitar os bacharéis em Ciências Sociais formados pela UFSM para a docência no ensino médio, atendendo à obrigatoriedade legal que começaria a vigorar a partir de 2008.

Meu estranhamento começa aqui, não só a partir da reação dos estudantes frente à minha inexperiência em face da inexistência de um programa para a Sociologia no ensino médio mas igualmente perante a formação de professores de Ciências Sociais na UFSM que reproduzia o modelo habitual brasileiro, sem questionar as finalidades e a eficácia curricular para uma disciplina em fase de implantação, que obviamente suscitava problemas de transposição/(re)contextualização didática e de seleção de conteúdo. A integraçáo curricular se deu em quatro semestres letivos e consistiu na oferta de disciplinas relativas à formação docente, tais como os Fundamentos da Educação (História e Sociologia da Educaçáo), bem como as disciplinas de Didática, focalizando metodologia do Ensino e os Estágios 
em escolas de Ensino Médio. A criação desta turma única se respaldou na exigência legal instituída pela Lei no 9.394, de 20 de dezembro de 1996 (LDBEN), e regulamentada pelo Parecer no 38/2006 do Conselho Nacional de Educaçáo que instituiu as disciplinas de Sociologia e Filosofia, como obrigatórias nas escolas de ensino médio no Brasil, a partir do ano letivo de 2008.

Outro estranhamento se referia à própria turma de estudantes e à história da educação que ministrava para esses egressos do Bacharelado em Ciências Sociais, em que as discussões de uma Antropologia da Educação, em termos da problematizar possíveis entendimentos de diversidade cultural e o próprio conceito de educação e de escola se sobrepunham ao programa clássico da disciplina que previa, por assim dizer, "Deus e sua época", partindo da educação em sociedades "primitivas" para chegar ao século XXI e a escola no mundo globalizado, mas sem tocar na escola brasileira em que atuariam.

Partindo dessa realidade, em que os estudantes colocavam em interrogação as próprias identidades do professor/licenciado em Ciências Sociais, tendo como espelho o bacharelado, e em que se envergonhavam de suas famílias por não saberem justificar o tipo de formação para ser professor nasceu o projeto como os sociólogos se tornam professores e o meu desejo de uma aproximação da discussão de formação de professores de Ciências Sociais no Brasil.

A pesquisa "Como os sociólogos se tornam professores?" foi concebida através do diálogo com os estudantes que cursavam a disciplina de História da Educação, e da interlocução com alguns docentes relacionados a este universo, do Departamento de Ciências Sociais e do Centro da Educação da UFSM. Nosso objetivo, na ocasião, era construir uma proposta de programa - uma espécie de roteiro - para auxiliar os professores do ensino médio a conduzirem a disciplina de Sociologia, uma vez que o seu projeto de implantação no ensino médio, exposto nos Parâmetros Curriculares Nacionais (PCNs) apenas apresentava diretrizes gerais. Efetuada uma análise preliminar, acreditávamos que esta situação dificultaria sobremaneira a atuação dos profissionais não cientistas sociais, conforme se configurou o panorama 
apresentado pela Secretaria Estadual de Educação naquela ocasião. A inexistência de conteúdos programáticos pareceu surpreender a todos: sociólogos, professores de áreas afins, estudantes e comunidade em geral.

$\mathrm{O}$ quadro anterior nos encaminha à reflexão de, pelo menos, duas questóes: as razóes expostas nas Orientaçôes Curriculares Nacionais (OCNs) que justificam a inexistência do dito programa e nosso desejo de construir uma proposta para a cidade de Santa Maria, em uma oposição que, em princípio, pareceu chegar às raias da contradição e de um posicionamento na contramão da proposta do próprio MEC para a ressurgência do ensino de Sociologia, cujas razóes encontram-se expostas de forma esparsa ao longo das OCNs:

[...] diferentemente das outras disciplinas escolares, a Sociologia não chegou a um conjunto mínimo de conteúdos sobre os quais haja unanimidade, pois sequer há consenso sobre alguns tópicos ou perspectivas. (BRASIL, 2006, p. 115).

[...] Acresce que a escola básica e, em especial, o ensino médio foram constituindo uma cultura própria - o que muitas vezes se chama cultura escolar -, em que saberes produzidos pelas pesquisas acadêmicas são transformados em saberes escolares, com características próprias, definidas por um contexto de ensino em que se redefinem os tempos, os conteúdos, os métodos, as avaliações e as condições do aprendizado dos alunos. (BRASIL, 2006, p. 108).

A diversidade de enfoques teóricos permite-lhes entender que um fenômeno social não tem apenas uma explicação [...] na medida em que existem diversas abordagens teóricas de um mesmo fenômeno. (BRASIL, 2006, p. 125).

O Ensino Médio pode ser entendido como momento final do processo de formação básica, uma passagem crucial na formação do indivíduo, por isso a presença ou ausência da Sociologia é desde já indício de escolha, sobretudo no campo político. (BRASIL, 2006, p. III).

Um dos grandes problemas que se encontram no ensino de Sociologia tem sido a simples transposição de conteúdo e práticas de ensino no nível superior, para o nível médio. (BRASIL, 2006, p. 108).

É possível trabalhar com muitos temas, "dependendo do interesse do professor, dos alunos e também da própria escola”, adequar o tema escolhido da própria realidade. (BRASIL, 2006, p. 119).

[...] os recursos aos temas visam a articular conceitos, teorias e realidade social partindo-se de casos concretos. (BRASIL, 2006, p. 120). 
O contexto histórico em que viveram esses autores [Marx, Weber, Durkheim], as influências intelectuais e a participação deles nos debates [...] definiram como cada um construiu seu arcabouço teórico. (BRASIL, 2006, p. 123).

O professor pode partir da apresentação da teoria do autor, reconstruindo-a numa linguagem acessível, mas rigorosa, tendo como referências principais alguns temas e conceitos que podem ser destacados e discutidos com os alunos para garantir a compreensão de uma teoria científica, sua linguagem, seus objetos e métodos de pesquisas, e suas relações com a realidade. [...] teoria, temas e conceitos devem estar articulados previamente no discurso do professor, de modo que fique claro que há uma necessidade de integração entre os temas abordados, não aparecendo esses como arbitrários. (BRASIL, 2006, p. 124).

Nosso posicionamento e nossa perspectiva de trabalho afloraram da própria análise das OCNs. Conforme mencionamos, a Sociologia era pensada como uma "ficção idealizada" para o Ensino Médio. Um vir a ser construído pelo exercício do professor. Ele deveria ser o intérprete por excelência destas orientaçóes e criar soluçóes (produzindo temas e abordagens), que a própria equipe de Cientistas Sociais que concebeu tais orientaçóes optou por não explicitar. Tais como: abordagens teóricas, seleção de conteúdos e materiais didáticos capazes de transpor a linguagem científica da Sociologia acadêmica para o universo do ensino médio. Então, caberia ao professor adaptar a cultura escolar os saberes adquiridos na Sociologia científica?

Diante desse quadro de orientaçóes, a perplexidade se instalou e começou a perpassar nosso percurso. Os estudantes, já bacharéis em Ciências Sociais e licenciados em formação, questionavam-se a respeito da abordagem mais adequada e suas implicaçóes. Soma-se a isto que, nas experiências de estágio curriculares em que foram inseridos, via de regra, surgiu o apelo das escolas para que formulassem uma proposta de programa, produzissem polígrafos e/ou que indicassem manuais compatíveis com a realidade do ensino médio devido à novidade da proposta apresentada.

Nossas reuniōes com a Secretaria Estadual de Educação em Santa Maria, já no cenário do projeto, financiado pelo PROLICEN (Programa de Licenciaturas) durante seis ediçóes, revelaram uma situação muito particular: a quase inexistência de professores de ensino médio com formação em Sociologia. A disciplina, em fase de implantação e com carga horária 
semanal (1 hora/aula de 45 a 50 minutos) vinha sendo ministrada por historiadores, filósofos, geógrafos e mesmo por matemáticos.

Sem qualquer desmerecimento de nossa parte com relação aos profissionais supracitados, o fato é que a situação de implantação da Sociologia no ensino médio nos apresentou situaçóes dramáticas que produziram perplexidade; afinal, giravam em torno da inexistência de conteúdo específico, da carência de profissionais da área, perpassada por carga horária semanal inadequada, o que se somou, nos anos subsequentes, à abertura de pouquíssimas vagas para concurso de professores estaduais, bem como escassas contrataçôes de professores de Ciências Sociais. De fato, nossas inquietaçóes se comunicavam diretamente com as incertezas presentes na maior parte do Brasil, conforme demonstram Bodart e Pereira (2017, p. 2, ) na apresentaçáo do volume 1 do "Caderno da Associação de Ensino de Ciências Sociais":

Ainda que tenhamos um crescente volume de pesquisas em torno do ensino de Sociologia, muitas perguntas já formuladas ainda não encontraram respostas satisfatórias, assim como muitas indagações que virão a ser fundamentais à consolidação desse subcampo de pesquisa ainda não foram formuladas. Bodart e Souza (2017), observando os artigos publicados nos 24 dossiês sobre ensino de Sociologia, constataram que as três maiores preocupações presentes nos artigos são "a institucionalização da Sociologia escolar", "a formação de professores de Sociologia" e a "forma como o ensino dessa disciplina vem sendo percebida por professores e alunos". Nota-se que as preocupações estão diretamente ligadas a elementos importantes para o estabelecimento da presença da Sociologia no Ensino Básico, fato importante para a consolidação do subcampo de pesquisa.

Concomitantemente ao desenvolvimento da pesquisa "Como os sociólogos se tornam professores”, o Departamento de Ciências Sociais, através do edital REUNI e da interlocução com a UAB, efetuou a proposta de criação de dois cursos de graduação e de um curso de especialização, conforme abordaremos a seguir.

\section{Os cursos de Licenciatura em Sociologia da UFSM}

De acordo com Ileizi Silva: "As idas e vindas da Sociologia nos currículos das escolas de ensino fundamental e médio constituem-se em um amplo objeto de estudos e em um programa de investigaçóes ainda em fase 
de estruturação no campo de pesquisas da educação e das Ciências Sociais" (SILVA, 2010, p. 23).

Neste sentido, entender a motivação para criação dos cursos em uma IES implica conhecer alguns elementos da sua história na regiáo em que se insere e a configuração de sua estrutura institucional. A fundação da Universidade Federal de Santa Maria se deu em 1960, inaugurando a interiorização do ensino superior no Brasil. Santa Maria está situada no centro do Rio Grande do Sul. em 2018, possuía 280.505 habitantes. É considerada uma cidade média e de grande influência na regiáo central do estado, especialmente em termos educacionais, já que congrega, além da UFSM, vários outros centros universitários e faculdades. ${ }^{2}$

O Departamento de Ciências Sociais da UFSM foi estruturado nos anos 1990, após a extinção do Instituto de Sociologia e Política que abrigava a oferta das disciplinas de Estudo dos Problemas Brasileiros (EPB) como resquício da ditadura militar em processo de abertura democrática. A cidade de Santa Maria que possui um dos mais significativos contingentes militares do Brasil, até a década de 1980 era considerada área de segurança nacional. A criação tardia de um curso de Bacharelado em Ciências Sociais se explica também por um forte lob institucional da entáo faculdade de História (ocorrido em 1995, que levou a negativa do Conselho de Ensino Pesquisa e Extensão de aprovar o Curso de Ciências Sociais) que temia o estreitamento do mercado de trabalho para seus egressos. O bacharelado em Ciências Sociais teve sua primeira turma formada em 2001.

Conforme Brum, Perurena e Oliveira (2013), o processo de criação e implantação dos cursos de Licenciatura no Departamento de Ciências Sociais na UFSM ocorreu entre 2007 e 2010. Em agosto 2007, em edição única, foi criada uma turma especial (já referida) para oferecer formação docente a fim de que os bacharéis em Ciências Sociais, egressos da UFSM, pudessem ser habilitados para ministrar aulas de Sociologia no ensino médio.

A primeira turma do Curso de Licenciatura em Sociologia, modalidade aberta, da Universidade Federal de Santa Maria, ingressou no segundo

2 As informações sobre o município foram consultadas em http://www.scielo.br/pdf/sant/u5n3/2236-7527sant-05-03-0935.pdf 
semestre de 2009 (um semestre antes da modalidade presencial). Foram oferecidas 200 vagas divididas igualitariamente entre os polos presenciais de Agudo (RS), Foz do Iguaçu (PR), Restinga Seca (RS), Santana do Livramento (RS) e Tio Hugo (RS). A distância de alguns destes municípios do polo sede (UFSM) merece destaque pelas implicações de deslocamento e gestão que acarretou e pelas enormes dificuldades para a formaçáo de professores que se apresentaram.

Quando se fala em Universidade Aberta do Brasil, estamos fazendo referência ao sistema que integra universidades públicas para oferta de cursos de ensino superior, tendo como prioridade a formaçáo de professores para educação básica, com a finalidade de expandir e interiorizar o ensino superior, já bastante representado nos grandes centros do país. Municípios com baixo IDH e IDEB têm precedência para abertura de polos de apoio presenciais, conforme Brum, Perurena e Oliveira (2014a, p. 7).

Ademais, para Brum, Perurena e Oliveira (2013, p. 51), a escolha pelo nome Sociologia provocou desde o processo de implantaçáo dos cursos presenciais e a distância vários desentendimentos e contradiçóes. O nome de Licenciatura em Sociologia adotado pela UFSM enfatiza uma preponderância da Sociologia na disciplina de Sociologia no ensino médio em detrimento das demais áreas de Antropologia e Ciência Política, que compóem as Ciências Sociais no Brasil. Vale lembrar que as OCNs assinalam essa perspectiva inclusiva dos conteúdos na disciplina de Sociologia, embora seja importante salientar na esteira de Luiza Helena Pereira (2013, p. 13) que a luta pela ressurgência da disciplina de Sociologia no ensino médio tenha sido capitaneada pelos sociólogos.

Para Brum e Oliveira (2014), a história recente da criação dos cursos se comunica com um cenário nacional de expansão. As particularidades deste processo na UFSM, que em boa medida explicam o que consideramos como problemas e distorções na formação de professores de Sociologia $\mathrm{EAD}$, podem ser compreendidas pelas motivaçôes e pelos mecanismos que culminaram pela opção de aderir, ao que denominamos, "pacote UAB e REUNI” bem como pelos direcionamentos apontados no PPC do curso e seu funcionamento, obviamente correlacionados com este processo.

Como o ensino a distância não tem um fluxo contínuo, mas depende de financiamento da CAPES, a cada nova possibilidade de ingresso o DCS 
da UFSM delibera sobre a criação de uma nova turma e o número de vagas a distribuir entre os polos. As ofertas têm gerado uma enorme polêmica. Há uma forte pressão institucional no sentido do oferecimento de novas turmas do Curso de Licenciatura em Sociologia EAD, em razão das duas vagas que foram recebidas pelo DCS. Um dos motivos foi o envolvimento (a vinculação) de vários docentes do DCS com o curso de especialização em Sociologia (modalidade EAD) que tem por objetivo habilitar profissionais de outras áreas do conhecimento para serem professores de Sociologia no ensino médio.

Em caráter conclusivo, cabe ressaltar, conforme esclarecem Brum e Oliveira (2014), que em que pesem os esforços das instituiçóes públicas em tentar manter o mesmo padrão de qualidade em termos de formação dos cursos presenciais, deve-se reconhecer os limites postos, os quais se referem, principalmente mas não exclusivamente, ao descompasso existente entre a forma de produção de materiais didáticos e as necessidades postas na produção do conhecimento das Ciências Sociais. Deve-se acrescentar a este cenário, ainda, a falta de preparação dos professores para atuar no ambiente virtual - o que parece indicar que a formação ofertada pela UAB é insuficiente para suas próprias demandas, ou, analisando por outro ângulo, que o curso a distância acentua e torna mais visível os nossos limites na capacidade de ofertar cursos de formação de professores e ainda os problemas de infraestrutura encontrados em vários polos pelo Brasil.

Ainda que possamos reconhecer a UAB como uma possibilidade de democratização do acesso ao Ensino Superior, especialmente aos cursos de Ciências Sociais, ainda muito concentrados em capitais e cidades de médio porte, devemos ter em vista os limites impostos por essa modalidade de ensino ante às especificidades existentes no processo formativo das Ciências Sociais, visto que o acesso às obras de autores clássicos e contemporâneos, brasileiros e estrangeiros, mostra-se fundamental. Como havíamos ponderado, as experiências ainda não incipientes junto às Universidades Públicas; assim, os elementos que buscamos trazer aqui a partir dos dois cursos visam a indicar questóes que se façam relevantes para pensarmos que novos desafios estão sendo postos ao cenário da formação de professores de Sociologia no Brasil. 


\section{A Licenciaturas em Sociologia e a Licenciatura em Ciências Sociais}

A criação do Curso de Licenciatura em Sociologia foi um processo demorado e negociado na instituição, especialmente entre a Pró-Reitoria de Graduação, o Centro de Educação e o Centro de Ciências Sociais e Humanas, ao qual se vincula o Departamento de Ciências Sociais. O motivo principal se cingiu à distribuiçãao de vagas docentes e ao monopólio dos cursos de formação de professores exercido pelo Centro de Educação. O Projeto Pedagógico do Curso de Licenciatura em Sociologia foi o resultado final desta barganha por vagas docentes, com acomodação das disputas entre os departamentos, frente às particularidades necessárias à formação de professores de Ciências Sociais, conforme demonstramos em Brum, Perurena e Oliveira (2014b).

O PPC respeitou as configuraçóes de campo já mencionadas de uma pretensa divisão de poderes e saberes acadêmicos em que o Centro de Educação, através de seus departamentos, concorria com as disciplinas didático-pedagógicas necessárias à formação de professores e o Departamento de Ciências Sociais com as disciplinas teórico-metodológicas atinentes às Ciências Sociais. A exceção a esta divisão se processou com duas disciplinas que ficaram lotadas no DCS: a Antropologia da Educação e a Sociologia da Educação.

A vinculação de ambas as disciplinas ao DCS se configurou em um importante diferencial do Curso de Licenciatura em Sociologia em que, como consequência, parte da discussão sobre formação de professores de Sociologia passou a ser capitaneada por Cientistas Sociais. Insisto sobre a importância desta abertura na formação de licenciados para atuação no ensino médio, pois: situar a educação como tema caro às Ciências Sociais, em suas particularidades, resultou do reconhecimento que cientistas sociais tinham algo a dizer sobre ser professor, para além e em diálogo com o quadro das disciplinas ofertadas pelos demais departamentos, que compunham o curso.

Nesta esteira, as reflexóes sobre ensino de ciências sociais e formação de professores, desde a concepção do curso, estiveram atreladas ao 
Departamento de Ciências Sociais, embora boa parte do quadro docente não possuísse qualquer formação ou afinidade com as reflexôes da licenciatura. A disciplina de Antropologia da Educação e minha própria inserção como docente, a partir de abril de 2009 ficaram vinculadas ao Departamento de Ciências Sociais. Como corolário, a Antropologia da Educação na UFSM, que nasceu no Centro de Educação, com o objetivo de fundamentar a formação de educadores especiais e pedagogos passou a se configurar e a se projetar como campo disciplinar vinculado às Ciências Sociais e a seus cursos de bacharelado, licenciatura e ao Programa de Pós-graduação em Ciências Sociais (BRUM; JESUS, 2018).

A disciplina de Antropologia da Educação vem sendo oferecida anualmente como obrigatória para o Curso de Licenciatura em Sociologia (que a partir de 2013 passou a ser denominado Licenciatura em Ciências Sociais) e como Disciplina Complementar de Graduação para o curso de Bacharelado em Ciências Sociais.

Nesse sentido, a disciplina foi amplamente reconfigurada. Sua nova proposição, ao fomentar o diálogo entre a Antropologia e a Educação extrapolou a apresentação dos conceitos antropológicos e a justificação de sua aplicabilidade na formação de pedagogos/educadores especiais e problemas de pesquisa. Sua ambição tanto na graduação como na pós-graduação em Ciências Sociais passou a se cingir à constituição de um campo na Antropologia para pensar a educação como um problema de pesquisa e de açáo caro aos cientistas sociais e, especialmente, aos antropólogos e antropólogos da educação estreitamente relacionada ao estudo da cultura.

\section{Antropologia da Educação e "Ciências Sociais para o ensino médio" para os cursos de Licenciatura em Ciências Sociais da UFSM}

O Curso de Licenciatura em Sociologia presencial em razão da Resolução UFSM 21/2013 recebeu a designação de Licenciatura em Ciências Sociais $\mathrm{O}$ processo foi deflagrado após a avaliação pelo MEC para reconhecimento do curso ocasião que foi avaliado com a nota 4 . Uma das razóes a discrepância entre a designação Sociologia e o PPC que apontava para a 
formação em Ciências Sociais o que igualmente percebemos ao analisar o PPC da Licenciatura em Sociologia EAD, apresentado acima.

A Licenciatura em Ciências Sociais /UFSM voltou a ser avaliado pelo MEC em 2018, obtendo nota 5, após a reforma curricular. Abaixo apresento as grades curriculares para em seguida elaborar uma análise concernente às disciplinas de Antropologia da Educação e Ciências Sociais para o ensino médio:

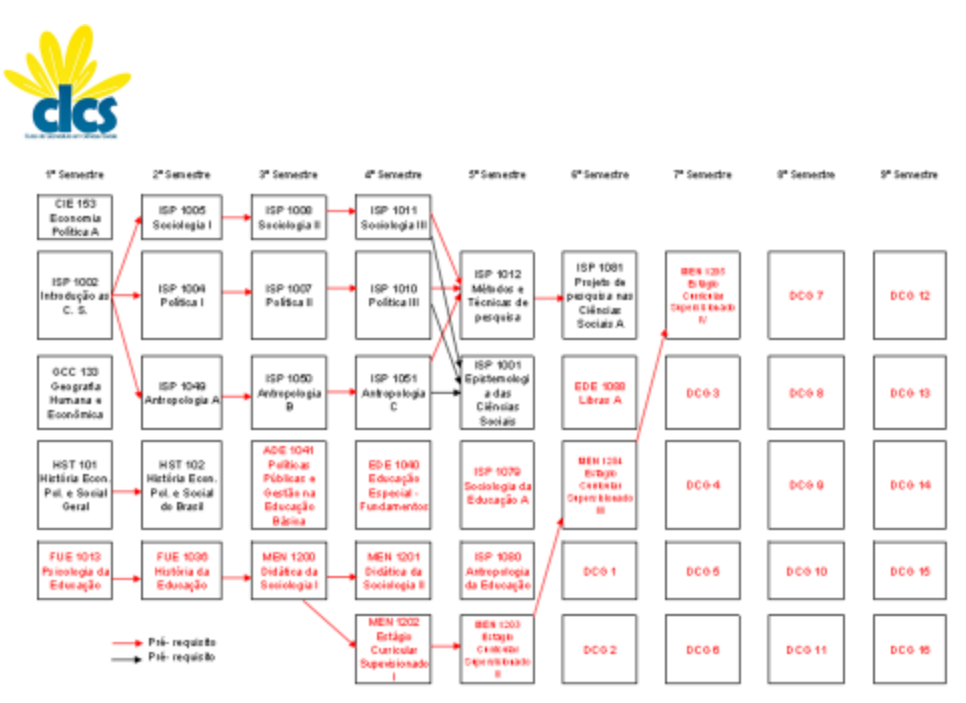

Fonte: PPPC de licencitura em Sociologia/UFSM 


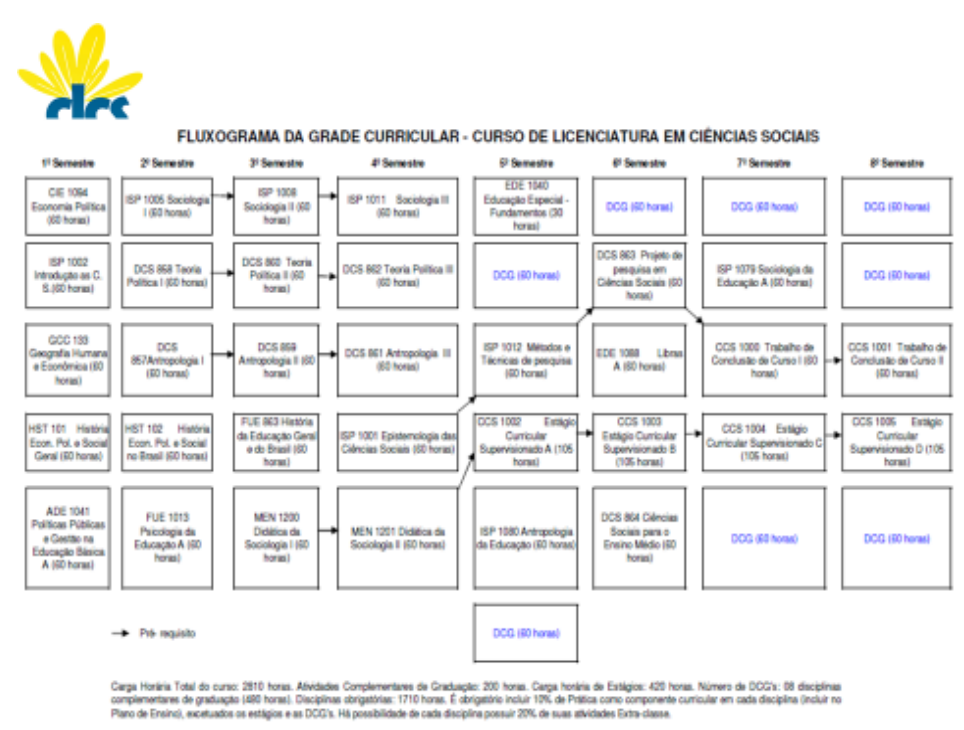

Fonte: PPPC do curso de licenciatura em Ciências Sociais/UFSM

A Antropologia da Educação já presente no PPC de Licenciatura em Sociologia continua a fazer parte do PPC de Licenciatura em Ciências Sociais no $5^{\circ}$ semestre de curso, juntamente com a Sociologia da Educação, e objetiva, conforme já salientado, estimular as reflexôes atinentes à educação como campo de estudo caro às Ciências Sociais e à formação de professores. Além disso, tal configuração curricular visa a efetuar a diferenciação da educação como problema sociológico, antropológico e suas interfaces.

A educação como corolário da cultura, em suas configurações, ocupa lugar central nas discussóes de Antropologia da Educação. A disciplina se constitui como uma antropologia especial para discutir educação como cultura (BRANDÃO, 2002), aprendizagem, cultura escolar, métodos e configuraçôes do campo, conforme os objetivos e o programa a seguir:

\section{ISPI080 ANTROPOLOGIA DA EDUCAÇÃO (4-0)}

OBJETIVOS: ao término da disciplina o aluno deverá ser capaz: de refletir sobre algumas matrizes do conhecimento antropológico - como as noções de cultura, identidade, aprendizagem, gênero, etnicidade, diferença e diversidade cultural, etnocentrismo, relativismo e multiculturalismo - relativamente ao contexto 
educacional e escolar brasileiro, em que atuará como cientista social e educador. Abordar os temas diversos relacionados à inclusão escolar, educação indígena, ciências sociais no ensino médio em suas particularidades no Brasil, incluindo a análise das políticas públicas e da legislação.

PROGRAMA: TÍTULO E DISCRIMINAÇÃO DAS UNIDADES

UNIDADE I - ANTROPOLOGIA

I.I - Por que estudar Antropologia da Educação em um Curso de Licenciatura em Ciências Sociais.

I.2 - A Antropologia Social e a Educação interfaces e desafios.

1.3 - A Antropologia na Educação e a Educação na Antropologia.

I.4 - A antropologia da Educação como campo de conhecimento: caracterização mundial e brasileira.

1.5 - A especificidade da prática antropológica, o trabalho de campo e a etnografia.

1.6 - Etnografia da Educação.

UNIDADE 2 - CULTURA E EDUCAÇÃO

2.1 - Cultura, conhecimento, educação e aprendizagem

2.2 - Os conceitos de cultura e civilização para a Antropologia da Educação

2.3 - A Cultura escolar

2.4 - Cultura e Identidade. Conceitos e interfaces nos processos educacionais formais e informais

2.5 - Relativismo, etnocentrismo e educação. Os PCN's e o respeito à diferença cultural.

UNIDADE 3 - CULTURA ESCOLAR

3.1 - Criança, juventude e ritos escolares.

3.2 - Estigma, Inclusão, exclusão e aprendizagem.

3.3 - As Ciências Sociais no Ensino Médio. Escola, ensino e docência.

3.4 - Etnicidade e educação. 
3.5 - Ações afirmativas no Brasil e o seu impacto na educação superior.

3.6 - Gênero, sexualidade, família, violência e educação.

A atual configuração do programa da disciplina já atende às exigências da reforma das Licenciaturas ${ }^{3}$, que vem sendo debatida na UFSM desde 2015. O ensino da Antropologia da Educação na Licenciatura em Ciências Sociais que objetiva potencializar a discussão da educação como um dos campos de estudo da Antropologia, ao dialogar com as demais antropologias presentes no PPC, enfoca a história da Antropologia Social e Cultural como campos de conhecimento no que concerne à educação em seus desenvolvimentos específicos. As relações entre Antropologia e Educação são trabalhadas em escala mundial (Levitt-Anderson, 2006) e brasileira (GOMES; GOMES, 2012) com o intuito de caracterizar não apenas sua especificidade da área em diferentes contextos históricos e geográficos, mas o movimento contínuo e dinâmico destes processos. A Antropologia da Educação é trabalhada como um campo em construção e pleno de disputas, especialmente às relativas aos embates teóricos, metodológicos e epistêmicos que caracterizam as relaçóes entre a Antropologia e os Estudos culturais, conforme (GUSMÃO, 2008).

No Brasil, tal fato adquire dimensóes epistemológicas importantes, pois permite aos estudantes perceberem que os processos de construção de identidades nacional e regionais no Brasil, são problemas educacionais de amplas dimensóes. $\mathrm{O}$ tratamento dado ao racismo, que vem sendo invisibilizado ao longo do processo histórico brasileiro, através da ideologia da mestiçagem conforme Munanga (2003) e as transformaçóes relativas à educação indígena, as quotas sociais e raciais nas universidades brasileiras que ocupam um espaço considerável são bons exemplos das potencialidades deste trabalho na formação de professores de Ciências Sociais, entre outros.

As discussóes metodológicas ocupam um lugar importante ao longo da disciplina e tem por intuito desenvolver reflexôes sobre as potencialidades da etnografia como método de investigação na escola conforme propóem

3 Conforme preconizado na Resolução CNE/CP 2/2015, publicada no Diário Oficial da União, Brasilia, em 2 de julho de 2015, seção I, p. 8-12. 
Amurabi Oliveira (2013a, 2013b) e Rockwell (2009), bem como o compromisso de uma vigilância metodológica proposta por Fonseca (1999). Fundamentalmente a antropologia da educaçáo deseja se apresentar como um espaço possível de estudo e pesquisa de processos de transmissáo cultural sejam eles formais ou não. Daí a necessidade de se relativizar, conforme Manuela Carneiro da Cunha (2009), o conhecimento científico como uma das formas de conhecer o mundo, mas não a única.

É nesse sentido que o investimento em reflexões sobre cultura, aprendizagem e educação são centrais na disciplina. De um lado, permitem aproximar à educação da cultura como um processo humano que acompanha nossa passagem pelo planeta, como ressalta Brandão (2002). Processos de habitar o mundo como preconiza Michel Serres (2001, p. 7) se relacionam à aprendizagem como viagem e marcha dinâmica.

$\mathrm{Na}$ Antropologia da Educação, a aprendizagem é deslocada de sua dimensão biológica (de mais ou mais bem aparelhados para aprender) como decorrente de um processo inato de acumulação de representaçóes, conforme preconizam os cognitivistas, para um investimento em suas dimensóes situacionais que valorizam o sujeito em sua relação ecológica com o contexto deste aprendizado. Assim, aprendemos com a desconstrução dos estereótipos, de uma aprendizagem baseada na superação de estigmas como no concernente às percepçóes sobre a educação dos portadores de altas e baixas habilidades. Buscamos alternativas mais humanas valorizadoras de suas vivências, conforme propóe Van der Weid (2015).

Os processos de avaliação são processuais e contínuos, incentivando os estudantes a interpretar e criar a partir das leituras dos textos propostos por mim e de temáticas escolhidas por eles, em aproximação com suas experiências de pesquisa o que provoca muitas vezes desconforto e inquietação, porque o campo é ainda visto como algo mitificado e ritualizado. Essa ênfase na pesquisa e na escrita como aprendizados me levou a concepçáo de uma Disciplina Complementar de Graduação denominada Etnografia e Educação e o diálogo com a disciplina Ciências Sociais para o Ensino Médio.

Como aprendizados desta experiência em curso e que se renova a cada semestre letivo, neste cenário de fricção e diálogo com estudantes e colegas de instituição, destaco a sensibilidade para a leitura de novos contextos 
formativos caracterizados por uma constante mudança de legislação e por processos de desumanização dos professores e da cultura escolar, corporificados em projetos como a Escola sem Partido. "Uma andorinha não faz verão", como diz o ditado popular. A formação de professores é um projeto coletivo descrito nos PPC e vivido por meio de múltiplas atividades de ensino, pesquisa e extensão dentro e fora da universidade.

\section{"Ciências Sociais para o ensino médio"}

O trabalho de concepção deste seminário remete ao já mencionado projeto "Como os sociólogos se tornam professores", no momento em que a Comissão Permanente de Vestibular nos convidou para desenvolver os conteúdos a serem exigidos no extinto vestibular da UFSM. O desafio da escrita de materiais didáticos como processo da aprendizagem de ser professor de Ciências nos acompanha desde então.

\section{Objetivos:}

Ao término da disciplina o estudante/pesquisador deverá ser capaz de articular as matrizes dos conhecimentos teóricos da Sociologia, Antropologia e Política com sua prática pedagógica no ensino médio, através da produção de recursos didático-pedagógicos baseada em uma ampla reflexão sobre a especificidade da disciplina e seus desafios.

PROGRAMA

UNIDADE I - AS CIÊNCIAS SOCIAIS NO ENSINO MÉDIO

I.I. Por que ensinar Ciências Sociais no Ensino Médio?

1.2. História e legislação

1.3. O novo ensino médio

UNIDADE 2 - EDUCAÇÃO E ESCOLARIZAÇÃO

2.I. Cultura, educação, linguagem e aprendizagem: conceitos e articulações

2.2. Escola, ensino e docência

\subsection{Ritos escolares}

2.4. Cultura escolar e a especificidade da prática pedagógica das Ciências Sociais no Ensino Médio 
2.5. Os manuais de Ciências Sociais no Brasil

UNIDADE 3 - PRÁTICA PEDAGÓGICA

3.I. Revisitando as disciplinas teóricas das Ciências Sociais em sua dimensão prática: a seleção de conteúdos e a produção de recursos didático-pedagógicos

3.2. Antropologia

3.3. Sociologia

3.3. Política

3.4. Limites, possibilidades e desafios

O principal objetivo, desde a sua criação, foi propiciar aos estudantes de Licenciatura em Ciências Sociais uma experiência de autoria de um capítulo voltado para o ensino de Sociologia no ensino médio, a partir da escolha de temas de qualquer uma das três áreas das Ciências Sociais. Até chegarmos a este momento de escrita e de suas apresentaçôes e amadurecimento do texto, mediante debates em sala de aula nós trilhamos um caminho que defino como de contato como o ensino de sociologia na escola brasileira.

Iniciamos com uma breve abordagem histórica e legislativa até chegarmos à Lei no 11.684/2008 e dialogamos com algumas experiências de ensino/aprendizagem em Sociologia publicadas em revistas da área nos últimos dez anos. A incorporação de uma abordagem antropológica da Sociologia no ensino médio não se resolve apenas pela inclusão de conteúdos mais caros à Antropologia. É preciso criar um entendimento entre nossos futuros professores de Sociologia que eles irão trabalhar em uma perspectiva abrangente das Ciências Sociais no ensino médio. Isto passa também pelas reflexóes que a Ciência Política e, especialmente, a Antropologia possam propor sobre os processos de ensino/aprendizagem e sobre as transformaçóes impostas pelo cenário brasileiro contemporâneo que tende a desconstruir via BNCC a importância da Sociologia e da Filosofia no ensino médio, no meu entendimento.

Na versão atual da disciplina, na qual estou trabalhando neste momento, abrimos um espaço privilegiado para discutir a reforma do ensino médio proposta na Lei no 13.415/2017, a Base Nacional Comum Curricular 
e a escola sem partido. Em um segundo momento, passaremos ao debate sobre conhecimento, aprendizagem e linguagem das ciências sociais no ensino médio que se relacionam ao debate sobre transposição didática e (re) contextualização dos conteúdos científicos, e a análise da cultura escolar. Entendo que uma discussão sobre os sentidos da escola para a juventude que passa por etnografias recentes das práticas escolares, tais como as ocupaçôes secundaristas e as percepçôes dos lugares do ensino médio na vida dos estudantes, é fundamental de ser pensada por futuros professores.

Acredito que a escrita deve ser parte integrante da vida do professor e de sua preparação. Nos cursos de formação de professores, creio que este aspecto vem sendo bastante negligenciado. Vivenciar a produção de material didático através da escrita é a nossa proposta de desenvolvimento da prática como componente curricular na disciplina de Ciências Sociais para o ensino médio, na UFSM.

\section{Considerações sobre a BNCC e a reforma do ensino médio: algumas digressões}

A breve apresentação de meu percurso, a descrição da configuração dos cursos no Departamento de Ciências Sociais na UFSM, as atividades de pesquisa e trabalho com as disciplinas de Antropologia da Educação e de Ciências Sociais para o ensino Médio têm aqui a intenção de apresentar a particularidade de um trabalho com a formação de professores em Ciências Sociais na IES que encerra contradiçôes e desafios com o qual grande parte das Ciências Sociais brasileiras vêm se deparando. A polêmica do final da obrigatoriedade da disciplina, a retenção e a evasão nos cursos de licenciatura (especialmente os noturnos e na modalidade educação a distância), a incerteza do momento vivido e as mudanças que a reforma do ensino médio e a Base Nacional Comum Curricular anunciam têm sido parte importante do nosso cotidiano e exigem, para além de um balanço, uma tentativa de interpretação, posicionamento e diálogo.

Dos duros golpes desferidos pela BNCC, que substitui as disciplinas das Humanas por um itinerário formativo que dilui História, Geografia, Sociologia e Filosofia, fica a mensagem subliminar de que há um desejo consciente por parte das políticas públicas atuais de diluir as licenciaturas. 
Quiçá de fechá-las na maior parte das IES em que ainda subsistem. Algumas questôes que se apresentam neste cenário:

- Como dialogar com esta situação em um contexto em que os professores que formamos têm um viés disciplinar? Em que os professores nas escolas irão disputar o direito de continuar trabalhando e terão de conviver com o fantasma dos profissionais detentores de notório saber (sem formação em licenciatura) que se anuncia como alternativa para a ausência de novos concursos?

- Como dialogar com o ensino médio em tempo integral que reconhece português, matemática e língua estrangeira? Quais alternativas possuímos como formadores de professores de Ciências Sociais neste cenário? Minha proposta é de que, além de pensarmos o ensino de ciências sociais na escola, é preciso retomarmos os instrumentos das Ciências Sociais para analisar a escola e propormos reflexôes. Tentarei fazer aqui algo concernente à Antropologia, à Antropologia da Educação.

Se retomarmos a análise do processo que levou à modificação do cenário do ensino médio, há algumas questóes que merecem ser destacadas. A primeira é a impopularidade da promulgação da lei que não reflete os anseios dos professores e da população em geral.

Para fazer algo em face de tantos desafios e insatisfaçóes, fica aqui meu entendimento da necessidade de recuperarmos o conceito antropológico de educação, na esteira de Brandão (2002, p. 143) como um tema central para a Antropologia. Afinal, para esse autor, toda a educação é cultura: "Toda a teoria da educação é uma dimensão parcelar de alguns sistemas motivados de símbolos e de significados de uma dada cultura, ou de um lugar social de entrecruzamento de culturas" (BRANDÃO, 2002, p. 139). Nesse sentido, vale também nos aproximarmos das proposiçóes de Tim Ingold de uma antropologia como educação - título de um livro recentemente publicado "Anthropology and/as education" (INGOLD, 2018) e já bastante discutido por antropólogos e educadores, onde desenvolve um amplo debate sobre as dimensóes educativas da Antropologia.

Para o autor a Antropologia não se reduz a um campo do conhecimento a estudar e ensinar, mas "a educação em sua constituição mesma" (INGOLD, 2018, p. 9). Ao abordar o cenário dos cursos de Antropologia 
em que ocorre a recepção do saber antropológico descrito nos manuais da disciplina Ingold percebe, para além de um lugar de transmissão, um local criativo em que se rememora o saber dos predecessores, para se ir mais além, logo: um trabalho educativo desenvolvido com cumplicidade entre o autor/professor e seus estudantes. Mais do que isso, para esse autor, no atual cenário universitário a Antropologia pode inverter "as torres de ébano”. Ela tem um papel emancipador (INGOLD, 2018, p. 93-94), uma vez que é capaz de mostrar as relaçóes de poder subjacentes às hierarquias tradicionais de saber e questionar as razóes universais e objetividade empírica sobre as quais repousam.

É nesse sentido que acredito no investimento em reflexões sobre cultura, aprendizagem e educação como centrais na formação de professores em Ciências Sociais. De um lado, permitem aproximar a educação da cultura como um processo humano que acompanha nossa passagem pelo planeta, como ressalta Brandão (2002). Processos de habitar o mundo, como preconiza Serres, relacionam-se à aprendizagem como viagem e marcha dinâmica:

Voici donc le prècepte en réponse, encore n'emmenez rien de ce qui difere du corps nu. Par conséquent ne garde que son entrainement, sa force propre, sa souplesse, ses capacités, son éveil adaptatif, sa langue, sa culture, sa science: rien de cela ni pèse ni ne ce voit; pars avec le plus lèger, c'est à dire ce que tu peux ou ce que tu sais: cela suffit; apprends donc pour quitter. Quitter pour apprendre. (SERRES, 200I, p. 6).

Et apprendre toujours, consiste à partir. Le plus léger bagage ne compte pas, ne se voit pas, ne pèse pas, puisque le corps l'assimila [...] Habiter a pour racine et origine le verb avoir; celui qui voyage n'a plus rien; le voici alors bien force d'être. Le mot pédagogie signifie ce voyage et l'apprendissage élève l'être en l'enseigmant qu'on peut se moquer d'avoir. (SERRES, 200I, p. 7). ${ }^{4}$

4 Aqui está o preceito em resposta, mas não tire nada do corpo nu. Consequentemente, ela retém apenas seu treinamento, sua própria força, sua flexibilidade, suas capacidades, seu despertar adaptativo, sua linguagem, sua cultura, sua ciência: nada disso pesa nem vê; vá com o mais leve, isto é, o que você pode ou o que você sabe: isso é suficiente; então aprenda a sair. Pare de aprender. (SERRES, 200 I, p. 6, tradução livre).

E para sempre aprender, é sair. A bagagem mais leve não conta, não é visivel, não pesa, pois o corpo a assimila [...]. Viver tem como raiz e origem o verbo ter; quem viaja não tem nada; aqui está, então, bem estar. $A$ palaura pedagogia significa esta jornada e o aprendizado eleva-se, ensinando-se que se pode zombar de ter. (SERRES, 200I, p. 7, tradução livre). 
Esta aventura descrita como habitar o mundo é a própria definição de educação mencionada por Ingold (2008). Se pensarmos nas dificuldades colocadas pela BNCC em relação à diluição das disciplinas de Humanas, este pode ser um ponto de partida para se dialogar com o novo contexto formativo. Mas, nesse sentido, é preciso também refletirmos sobre as universidades por meio de um olhar que denuncie a transformação que sofreram ao longo dos três séculos de sua história para reinventá-las como espaço educativo em que a Antropologia tem papel fundamental. Para Ingold (2018, p. 93):

À l'instar d'autres instituitions publiques, des universités offrent des cibles faciles pour le mercntilisme. Mais rien ne prouve que les régimes de gestion qui se sont arrogé l'activité de controle de ce qu'ils appellent "le secteur"(le non qu'ils donnent a ce qu'il est devenu un marché mondial lucratif) mesurent bien les enjeux. Leur vision à court term de la éducation superieur se limite à des indices bruts de rang et de productivité. L'enseigment est indexé sur la satisfaction et capacite d'insertion professionnelle des étudiants, la recherché sur l'innovation et le potential commercial. Ces critères n'ont rien à voir avec l'éducation démocratique et sont sur le point de reproduire l'économie du savoir, avec l'affaiblissement de droits civiques et des inegalités inhérentes. La mission educative, don't les universités ont hérite des Lumières survit aujour'hui en théorie uniquiment. ${ }^{5}$

As digressóes de Ingold fornecem um quadro que nos possibilita dialogar com a estrutura de ensino e pesquisa no Brasil, em seus rígidos limites e perspectivas. Ela nos permite igualmente pensar nas consequências das transformaçóes que a reforma do ensino médio e a BNCC nos impóem. A universidade deve redefinir seus objetivos. A educação deve ser-lhe restituída. A formação de professores deve ser enfatizada, conforme propóe Nelson Tomazi (2017, p. 234) em entrevista ao "Cadernos ABECS":

Penso, ainda, que a ênfase deva ser dada na formação de professores, ou seja, no ensino da graduação nas universidades. No meu entender a graduação está abandonada nas universidades

5 Como outras instituições públicas, as universidades oferecem alvos fáceis para o mercantilismo. Mas não há evidências de que os regimes de gestão que se arrogaram a atividade de controle do que eles chamam de "setor" (o "não" que eles dão ao que se tornou um mercado global lucrativo) medem bem as questões. Sua visão de curto prazo do ensino superior é limitada a indices de produtividade e índices brutos. O ensino é indexado à satisfação e empregabilidade do aluno, pesquisa sobre inovação e potencial comercial. Esses critérios nada têm a ver com a educação democrática e estão prestes a replicar a economia do conhecimento, com o enfraquecimento dos direitos civis e as desigualdades inerentes. A missão educacional, da qual as universidades herdaram o lluminismo, sobrevive apenas na teoria de hoje. (INGOLD, 2018, p. 93, tradução liure). 
brasileiras. Com o advento das pós-graduações e com a implantação do Currículo Lattes, pouco a pouco, as graduações foram sendo deixadas de lado e as licenciaturas, que sempre foram vistas como marginais no processo, passaram a ser mais ainda, mesmo que o licenciado tenha o maior espaço de trabalho existente para os graduandos em Ciências Sociais. Assim, desenvolveu-se uma "cultura acadêmica" que não existe vida fora do Currículo Lattes e a pós-graduação é tudo o que importa. Desde cedo o aluno é encaminhado para fazer o seu Currículo Lattes e é isso o mais importante. A sua formação (no sentido da Bildung para T. Adorno) não é levada em conta. Há uma espécie de mercantilização do saber, onde o que importa é a pontuação naquela plataforma, principalmente por parte dos professores universitários.

Sáo características de uma cultura acadêmica, de uma cultura escolar universitária. A configuração da cultura escolar para Perez Gomez (2002) se inscreve em um conjunto de interfaces, conflitos e contradiçóes a que concorrem e interagem saberes, estrutura do campo científico e do conhecimento, de poderes políticos, econômico e jurídicos, as "culturas" dos grupos envolvidos neste diálogo e em disputa, apenas para citar alguns elementos desta dinâmica em constante transformação que ocorre também na cultura universitária.

Os cursos de Ciências Sociais no Brasil se caracterizam por uma formação/especialização "em conjunto e em diálogo" com a Sociologia e a Ciência Política. Cabe salientar que a formação se dá em termos da organização de disciplinas voltadas à especialização. Neste sentido, é preciso reconhecer que produzimos no Brasil uma cultura universitária que nos encerra em malhas disciplinares pouco maleáveis e que, de alguma forma, invisibiliza questóes fundamentais nestes processos, cujo melhor exemplo é a questão do ensino. Formamos cientistas sociais sem que tenhamos um espaço para pensar sobre sua formação, sobre a dupla dimensão pesquisador/ professor e suas implicaçóes. São raros os espaços para se analisar a escola como objeto de estudo das Ciências Sociais e do diagnóstico que este estranhamento pode produzir em seu potencial formativo e pedagógico. São raros ou inexistentes os espaços para a produção de material didático e para os exercícios de transposição e (re)contextualização didática.

A falta de preparo, a ausência de um diálogo sobre como ensinar/aprender soa como mais um dos desafios de uma cultura classificatória e meritocrática da universidade que é altamente formalizada e ritualizada e que silencia "não por acaso" sobre questóes fundamentais. Esta situação demonstra que a representação que temos da docência é algo menor, e que os obstáculos colocados nos processos de aprendizagem formal são espontaneamente 
superados pelos fortes porque possuem domínio de conteúdo; assim, isso seria o suficiente no mundo acadêmico para se chegar até a escola para ensinar.

Para Ingold (2018), a Antropologia pode se constituir em um processo educacional de amplo espectro que descentra e transforma visóes de mundo e suas percepçóes éticas. Sua perspectiva de uma Antropologia como educação vem fortalecendo meu desejo de refletir e atuar sobre a formação de professores nos cursos de Ciências Sociais e tem me levado a interrogar igualmente sobre os processos de ensino/aprendizagem, em seus contornos individuais e coletivos. É tempo de revermos as concepçôes de aprendizagem e de cultura escolar que animam nossos processos formativos. Refiro-me a proposta apresentada em Educação como Cultura.

Brandão (2002, p. 137-138) acrescenta sobre a aprendizagem:

Pois o que poderia parecer algo tão simples e tão redutível a uma meia dúzia de fórmulas e a
uma boa teoria única, na realidade esconde nos gestos de uma criança, toda a complexidade
do universo da consciência. Ela vai dos mistérios da decifração do DNA, até a compreensão
sobre como em cada cultura o acontecimento da aprendizagem - e de tudo o que envolve
em seu dia a dia social - é imaginado, codificado e vivenciado entre os seus sujeitos. [...]
Assim o mistério de aprender estende-se como nunca a uma possibilidade polissêmica de
descobertas e de integrações de ideias empíricas e teóricas.

Lave (2005, p. 57) aborda a aprendizagem para além dos seus limites de um processo cognitivo e individual. Para ela a aprendizagem é um fenômeno fundamental do qual o ensino pode ou não ser parte e que adquire principalmente a dimensão de produção de identidade, nos projetos de vida dos participantes em comunidades.

A dimensão disciplinar na formação de professores certamente nos impóe muitos desafios e fronteiras para o aprendizado. Um deles é o de imprimir espontaneidade e liberdade com reflexidade, na sua formação. Um processo do desenvolvimento de skills (habilidades) que se processa a partir do trabalho de campo para desvendar a própria escola em que se vai ensinar, corporificado em uma educação da atenção (INGOLD, 2010), para a diferença e sua interpretação. Outro importante desafio que certamente acompanha nossa tarefa de formadores é a do encantamento: de uma sedução para a descoberta de cenários culturais, dos sentidos de ensinar Sociologia no ensino médio sem descuidar dos aprendizados sobre 
a responsabilidade ética e política da tarefa de interpretação e atuação a ser realizada pelos professores de cientistas sociais que estamos formando.

Para além dos desafios da profissionalização e da precarização do mercado de trabalho, é necessário não perder a dimensão da educação como corolário da produção cultural humana, e entender seu sentido antropológico. Assim, considero fundamental uma recuperação antropológica do conceito de educação e a restituição às universidades de seu papel educativo, para além das exigências do mercado de trabalho, das flutuaçóes das legislaçóes e da transitoriedade de políticas impopulares para a educação.

\section{Referências}

Associação Brasileira de Ensino de Ciências Sociais (ABECS). Nota da Associação Brasileira de Ciências Sociais sobre a BNCC. abr. 2018. Disponível em: https://abecs.com.br/nota-bncc. Acesso em: 10 set. 2018 .

Bodart, C; Pereira, T. Apresentação. Breve balanço do subcampo "ensino de Ciências Sociais" no Brasil e o papel da Associação Brasileira de Ensino de Ciências Sociais - Cadernos Da Associação Brasileira De Ensino De Ciências Sociais | Vol.1, no.1 | p. 01-10 | Jan./Jun. 2017.

BRANDÃO, C. R. A educaçáo como cultura. Campinas: Mercado das Letras, 2002.

BRASIL. Lei no 9.394, de 20 de dezembro de 1996. Estabelece as diretrizes e bases da educação nacional. Disponível em: http://www2.camara.leg.br/legin/fed/lei/1996/lei-9394-20-dezembro1996-362578-publicacaooriginal-1-pl.html. Acesso em: 1 set. 2018.

BRASIL. Ministério da Educação. Orientaçóes curriculares para o ensino médio. Vol. 3 Ciências Humanas e suas tecnologias. Brasília: MEC, 2006. Disponível em: http://portal.mec.gov.br/seb/ arquivos/pdf/book_volume_03_internet.pdf. Acesso em: 1 set. 2018.

BRASIL. Lei no 11.684, de 2 de junho de 2008. Altera o art. 36 da Lei no 9.394, de 20 de dezembro de 1996, que estabelece as diretrizes e bases da educação nacional, para incluir a Filosofia e a Sociologia como disciplinas obrigatórias nos currículos do ensino médio. Disponível em: http:// www2.camara.leg.br/legin/fed/lei/2008/lei-11684-2-junho-2008-575857-publicacaooriginal99168-pl.html. Acesso em: 1 set. 2018.

BRASIL. Lei no 13.415, de 16 de fevereiro de 2017. ?. Disponível em: Ihttp://www.planalto.gov. br/ccivil_03/_ato2015-2018/2017/Lei/L13415.htm. Acesso em: 1 set. 2018.

BRASIL. Ministério da Educação. Base Nacional Comum Curricular. 2017. Disponível em: http://basenacionalcomum.mec.gov.br. Acesso em: 17 set. 2017.

BRUM, C. K.; PERURENA, F. C. V.; OliVEIRA, R. M. "Como os sociólogos se tornam professores”: da implantação dos cursos de Licenciatura em Sociologia na Universidade Federal de Santa Maria e seus impasses. In: MEIRELLES, M.; RAIZER, L.; PEREIRA, L. H. (Org.). O ensino de Sociologia no Rio Grande do Sul. 1. ed. Porto Alegre: LAVIECS, 2013. v. 1. p. 49-75. 
BRUM, C. K.; PERURENA, F. C. V.; OLIVEIRA, R. M. A construção e implantação dos cursos de licenciatura em Sociologia na Universidade Federal de Santa Maria. Saberes em Perspectiva, v. 4, n. 8, p. 51-73, 2014 a.

BRUM, C. K.; PERUREnA, F. C. V.; OliVeirA, R. M. A. Programa de Antropologia da Educação. PPC Curso de Licenciatura em Ciências Sociais. Santa Maria: UFSM, $2014 b$.

BRUM, C. K.; JESUS, S. C. Antropologia como educação: um diálogo sobre experiências de ensino da antropologia em cursos de formaçáo de professores e seus desafios. Ciências Sociais Unisinos, São Leopoldo, v. 54, n. 2, p. 217-228, maio/ago. 2018.

CUNHA, Manuela C. Cultura com aspas. São Paulo: Cosac Naify, 2009.

FERRETI, C. J.; Silva, M. R. da. Reforma do ensino médio no contexto da medida provisória no 746/2016: estado, currículo e disputas por hegemonia. Revista Educaçáo \& Sociedade, Campinas, v. 38, n. 139, p. 385-404, abr./jun. 2017.

FONSECA, Claudia. Quando cada caso não é um caso: pesquisa etnográfica e educação trabalho apresentado na xxi reunião anual da anped, caxambu, set. 1998disponhttp://www.anped.org.br/ rbe/rbedigital/rbde10/rbde10_06_claudia_fonseca.pdf

GOMES, A.; GOMES, N. L. Anthropology and education in Brazil: possible pathways. In: Anderson-Levitt, K. Anthropologies of education a global guide of ethnographic studies of learning and schooling Berghahn Books, 2012. p. 111-130.

GUSMÃO, N. M. M. Antropologia, estudos culturais e educação: desafios da modernidade. Proposiçóes, Campinas, v. 19, n. 3, p. 47-82, set./ dec. 2008.

INGOLD, T. Anthropology is not ethnography. British Academy: 2008. Disponível em: http:// proc.britac.ac.uk/tfiles/154p069.pdf. Acesso em: 10 set. 2018.

INGOLD, T. Da transmissão de representações à educação da atenção. Educaçáo, Porto Alegre, v. 33, n. 1, p. 6-25, jan./abr. 2010.

INGOLD, T. O dédalo e o labirinto: caminhar, imaginar e educar a atenção. Revista Horizontes Antropológicos, Porto Alegre, n. 44 (Dossiê Cultura e Aprendizagem), p. 21-36, 2015.

INGOLD, T. L'anhropologie comme éducation. Rennes: presses universitaires de Rennes, 2018.

LEVITT-ANDERSON, K. Les divers courants en anthropologie de l'éducation. Dossier Anthropologie de l'éducation pour un tour du monde. Éducation et societé, n. 7, p. 7-27, 2006.

MUNANGA, Cabengele. Algumas consideraçóes sobre a diversidade e a identidade negra no Brasil. In Diversidade e Educaçáo: reflexóes e experiências. MEC, 2003, P. 35-50.

OLIVEIRA, A.; BRUM, C. K. Ciências Sociais a Distância: apontamentos sobre os desafios da formação de professores no Brasil. O público e o privado, v. 1, p. 29-49, 2014. Disponível em: http://www.seer.uece.br/?journal=opublicoeoprivado\&page=article\&op=view \&path\%5B $\% 5 \mathrm{D}=8$ 31Acesso em: 10 set. 2018. 
Os 10 anos da Sociologia no ensino médio no Brasil: considerações sobre a formação de professores de Ciências Sociais na UFSM | Ceres karam Brum

PEREIRA, L. H. A luta dos sociólogos pela obrigatoriedade da Sociologia no ensino médio In: PEREIRA, L. H. O ensino de Sociologia no RS: repensando o lugar da Sociologia. Porto Alegre: LAVIECS, 2013. p. 13-34.

Perez Gomez A I. A cultura escolar na sociedade neoliberal. Rio de Janeiro: Saraiva (2002).

ROCKWELL, Elsie. La Experiencia Etnografica. Buenos Aires: Paidós, 2009.

SANTA MARIA IN WILKIPÉDIA

https://pt.wikipedia.org/wiki/Santa_Maria_(Rio_Grande_do_Sul) consulta em 30 de setembro de 2019.

SERRES, M. Habiter. Paris: Le Pomier, 2011.

SILVA, I. L. F. O ensino das Ciências Sociais/Sociologia no Brasil: histórico e perspectivas. In: MORAES, A. C. (Coord.). Sociologia: ensino médio. Brasília: Ministério da Educação, Secretaria de Educação Básica, 2010. p. ? (Coleçáo Explorando o Ensino; v. 15).

PEREIRA, T. "Foi neste processo que me tornei um divulgador da sociologia para o Ensino Médio" Entrevista com Nelson Dácio Tomazi in Cadernos da Associação Brasileira de Ensino de Ciências Sociais | Vol.1, no.1 | p. 227-238 | Jan./Jun. 2017.

VON DER WEID, Olivia. O corpo estendido de cegos: cognição, ambiente, acoplamentos in sociologia\&antropologia | Rio de Janeiro, v.05.03: 935-960, dezembro, 2015http://www.scielo. br/pdf/sant/v5n3/2236-7527-sant-05-03-0935.pdf. Consulta em 10 de agosto de 2019.

\section{The 10 years of sociology in high school in Brazil: considerations about the formation of teachers of Social Sciences at UFSM}

\section{Abstract}

The article aims to evaluate the formation of Social Sciences teachers in Brazil, initiated with the enactment of Law No. 11,684 / 2008 (which made the teaching of Sociology and Philosophy in secondary education compulsory), which is completed with the reform of secondary education and the National Base outlined in Law no. 13,415 / 2017. For that, I intend to focus the work experience with the disciplines of Social Sciences for High School and Anthropology of Education, starting from the transformations that occurred in the Department of Social Sciences of the Federal University of Santa Maria (UFSM), which led to the creation of Degree in Sociology and Social Sciences in the face-to-face and EAD modalities. In a second moment, I intend to propose some reflexive actions for the times that are announced, effecting a recovery of the anthropological concept of education, to put it into action and, in the service of the training of graduates in Social Sciences in Brazil, to, as a conclusion, to express new avenues of access to social sciences in school.

Keywords: sociology, high school, teacher training

Recebido em: 04/10/2018

Aprovado em: 03/04/2019 